\title{
Modelling and dynamic analysis of a power system with integrated strategy of VSC-HVDC radial plus strategy
}

DOI:

10.1049/cp.2016.0307

Link to publication record in Manchester Research Explorer

\section{Citation for published version (APA):}

Barnes, M., Preece, R., \& Shah, R. (2016). Modelling and dynamic analysis of a power system with integrated strategy of VSC-HVDC radial plus strategy. In IET Power Electronics, Machines and Drives Conf, April 2016, Glasgow https://doi.org/10.1049/cp.2016.0307

\section{Published in:}

IET Power Electronics, Machines and Drives Conf, April 2016, Glasgow

\section{Citing this paper}

Please note that where the full-text provided on Manchester Research Explorer is the Author Accepted Manuscript or Proof version this may differ from the final Published version. If citing, it is advised that you check and use the publisher's definitive version.

\section{General rights}

Copyright and moral rights for the publications made accessible in the Research Explorer are retained by the authors and/or other copyright owners and it is a condition of accessing publications that users recognise and abide by the legal requirements associated with these rights.

\section{Takedown policy}

If you believe that this document breaches copyright please refer to the University of Manchester's Takedown Procedures [http://man.ac.uk/04Y6Bo] or contact uml.scholarlycommunications@manchester.ac.uk providing relevant details, so we can investigate your claim.

\section{OPEN ACCESS}


This paper is a postprint of a paper submitted to and accepted for publication by, and is subject to Institution of Engineering and Technology Copyright. The copy of record is available at IET Digital Library

\title{
Modelling and Dynamic Analysis of a Power System with VSC- HVDC Radial Plus Strategy
}

\author{
Rakibuzzaman Shah, M. Barnes, R. Preece \\ School of Electrical and Electronic Engineering, The University of Manchester, UK \\ E-mail: rakibuzzaman.shah@manchester.ac.uk;mike.barnes@manchester.ac.uk; \\ robin.preece@manchester.ac.uk
}

Keywords: AC-DC dynamics, Radial plus strategy, Transient stability, VSC control.

\begin{abstract}
This work presents the analysis of a radial plus VSC-HVDC scheme in terms of its impact on AC and DC system dynamics. This study uses the classical two-area system with modified demand as an onshore AC grid. Full converter wind power plants (WPPs) are connected to the main grid through two point-to-point VSC-HVDC links, which are connected offshore through an AC cable to form a 'radial plus' strategy for VSC-HVDC connection. A variety of different control schemes for the radial plus VSC-HVDC are described and analysed to find out the impact of these controllers on the dynamic behaviour of the system. Simulation results are presented to illustrate the impact of different control combinations on system dynamic performance under various grid disturbances.
\end{abstract}

\section{Introduction}

The UK government has set an objective to reduce net carbon emissions by 2050 to $80 \%$ below 1990 levels. To achieve this target, the UK government has committed to $15 \%$ energy production from renewable resources by 2020 [1]. In accordance with the 2009 Renewable Energy Strategy, 30\% of the UK's electricity generation must come from renewable energy resources by 2020 [2]. Based on the renewable energy potential of UK, it is expected that at least half of this generation will come from offshore wind power plants (WPPs). Offshore WPPs of $35 \mathrm{GW}$ equivalent capacity are proposed to be connected to the UK's electricity network by 2035 [3]. Hence, a significant transmission infrastructure development is required to interconnect these resources to the existing grid. In general, HVDC would be a more favourable option than HVAC to connect the majority of Round 3 offshore wind resources, primarily due to the offshore connection distances involved.

Certain characteristics of VSC-HVDC (e.g., no voltage polarity reversal to reverse power flow, independent active and reactive power control, ability to connect a remote grid, a smaller footprint) make it preferable over CSC-HVDC (often called line commutated HVDC, LCC-HVDC) for offshore WPP integration [4]. Most of the present VSC-HVDC installations are point-to-point, however, the future extension into a multi-terminal DC (MTDC) grid is often discussed. The often proposed North Sea super grid to connect the countries in the region (e.g., UK, Germany, Netherlands, and Scandinavia) may be connected through offshore MTDC grids [5], [6]. The literature has proposed different configurations to form a coordinated or integrated VSCHVDC architecture for integrating offshore WPPs. However, the interconnection has been made on the DC side of the grid. These types of configurations require DC circuit breakers to ensure the secure operation of the HVDC grid in response to faults on the DC grid. Substantial research has been undertaken both by major manufacturers and academics in developing DC circuit breakers. Presently, such a DC breaker relies on a large DC reactor to limit the rate of rise of the fault current and the rate at which DC voltage reduces. As reported in [7], the large DC reactor will increase the electrical distance between the converter stations, have a detrimental effect on DC voltage control of the grid, and therefore, affect the stability of the system. Furthermore, the requirement of an expensive DC/DC converter to connect two existing point-topoint VSC-HVDC links with different DC voltages also limits the rapid development of VSC-HVDC grids.

According to [8], connecting the offshore WPPs to form an offshore grid would probably be the first stage of MTDC grid development. The UK Transmission System Operator, National Grid has proposed three strategies for connecting offshore WPPs, namely, 'radial', 'radial plus', and the 'integrated' strategy as shown in Fig. 1.

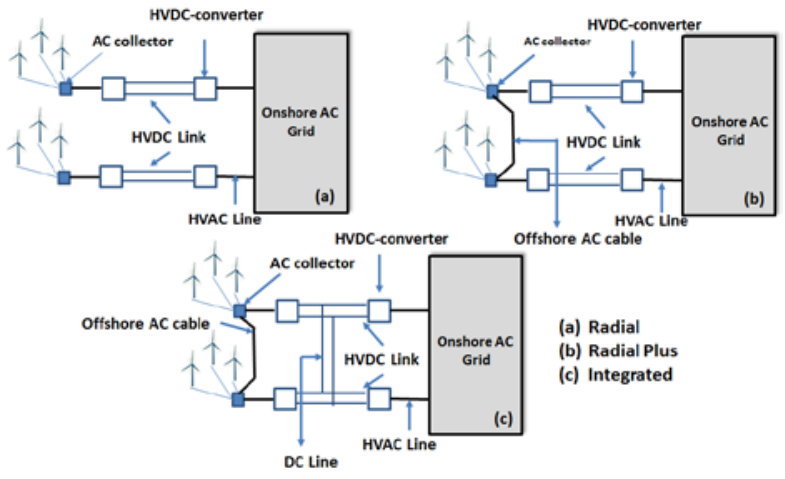

Fig. 1. Offshore WPP connection strategies [8].

The 'radial' and 'radial plus' schemes are mainly point-topoint configurations whereas the 'integrated' strategy interconnects neighbouring WPPs through short AC 
transmission cables to form an offshore AC grid and has a DC interconnection between VSC-HVDC lines. A similar idea to the 'radial plus' scheme, termed the 'Supernode' has also been proposed as a key concept of the first phase of the European 'Supergrid' [9], [10]. There are challenges to form and operate offshore AC grids including the control coordination among multiple converters. Two options have already been proposed in the current literature, namely, master-slave, and droop based control [8]-[10]. However, the study emphasis has been on the DC dynamics (e.g., DC-link voltage and power oscillation) of the system rather than the AC and DC dynamics of the combined power system. While limited previous efforts have investigated some of the impacts of connecting VSC-HVDC and LCC-HVDC electrically close to each other, very limited research effort have focussed on analysing the impact of two VSC-HVDCs connected close to each other. This study has therefore analysed the impact of a radial plus VSC-HVDC configuration on AC-DC dynamics of the system in the transient stability time frame under different control schemes.

\section{AC-DC System Model}

A mixed AC-DC test system for VSC-HVDC connection is shown in Fig. 2. The two-area system from [11] has been used as an onshore AC network. This test system is commonly used for dynamic analysis and has been integrated with VSC-HVDC systems for such studies in the past [4]. To necessitate the transmission of offshore wind power to the onshore system, the loads at bus 7 and 9 are increased by 750 MW. The WPPs consist of eight aggregated full converter wind turbines with total capacity of $1500 \mathrm{MW}$. As shown in Fig. 2, four 33/220 kV three winding transformers connect two of the aggregated WPPs at the low voltage side of four 220/325 kV step up transformers. The WPPs are connected to the onshore AC system by two parallel VSC-HVDC links. Each converter terminal in the system is rated at $800 \mathrm{MVA}$, $\pm 320 \mathrm{kV}$.

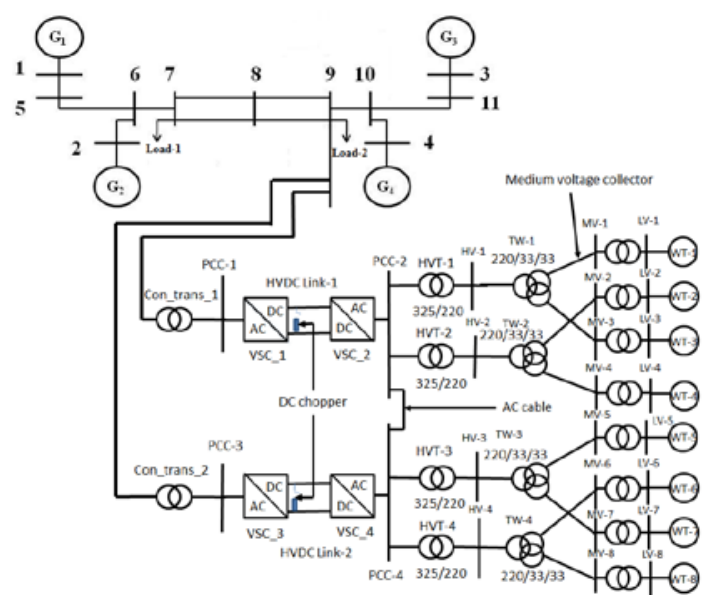

Fig. 2. Schematic diagram of AC-DC test system.

The two VSC-HVDC links are connected offshore by a $10 \mathrm{~km}$ cable to form an offshore grid. The system is modelled in DIgSILENT Power Factory 15.1 [12]. As depicted in Fig. 2, a DC chopper is modelled at the grid side VSCs to facilitate onshore fault ride through. In this study, the DC chopper has been modelled as a voltage controlled current source as presented in [13].

\section{VSC Control and Control Parameterization}

\subsection{VSC Control}

Converter control is used to control the voltage, current, and power in VSC-HVDC. A variety of cascaded outer loops can be added. The outer loops that are used in this study are briefly summarized next.

Feedback DC voltage loop - DC voltage of a HVDC system indicates the power balance in the DC system, similar to the frequency in an AC system. The DC voltage in a HVDC system is maintained by manipulating the power transfer into and out of the DC system by the VSCs. This can be obtained by adding an outer PI loop to control the d-axis reference current based on DC voltage [14].

Feedback active and reactive power loop - Fig. 3 shows the feedback active and reactive power control loop. These controls manipulate the active and reactive power to the reference values. The active power control is achieved by adding an outer PI loop to control the converter d-axis current while reactive power control is achieved by using an outer PI loop to control the q-axis converter current [14].

Feedback AC voltage loop - Fig. 4 shows the feedback AC voltage loop which regulates the AC side voltage of the grid in which the VSC is connected. For ' $\mathrm{dq}$ ' vector current control, AC voltage is controlled by adjusting the q-axis current reference signal [14].

Offshore AC voltage and frequency control - Fig. 5 shows the offshore AC voltage and frequency controller implemented in this study. This control is applied to a VSCHVDC link when it is connected to the offshore grid where the VSC is the only dominant voltage source. From the power system point of view it acts as a zero inertia generator which sets the frequency, voltage amplitude, and the phase angle for the offshore AC grid [15].

Droop type control - Besides DC voltage droop control for VSC-HVDC, droop control characteristics can be used in VSC-HVDC to contribute to the voltage support and frequency of the grid. In this study, the AC voltage and frequency droop characteristics are used in a VSC-HVDC system to adjust the AC voltage and frequency references. Fig. 6 shows the VSC-HVDC AC voltage and frequency droop characteristics. The AC voltage droop characteristic of a VSC-HVDC converter is similar to a STATCOM. The converter injects reactive power to the system during low AC voltage and absorbs reactive power while AC voltage is too high based on equation (1).

$$
V_{A C}=V_{A C \_r e f}+k_{Q s l o p e}\left(Q_{r e f}-Q\right)
$$

Frequency droop control is used to configure the VSC-HVDC system to contribute to the grid frequency support with other converters or sources (in this case synchronous generators). A 
power dependent frequency control approach [15] has been used in this study. The coordination among the VSCs is achieved based on equation (2).

$$
f=f_{\text {ref }}+k_{\text {fslope }}\left(P_{\text {ref }}-P\right)
$$

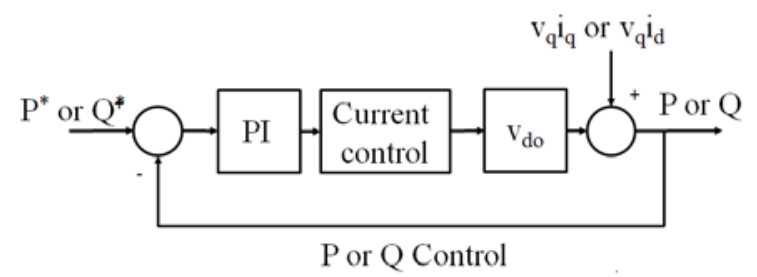

Fig. 3. Feedback active and reactive power control loop.

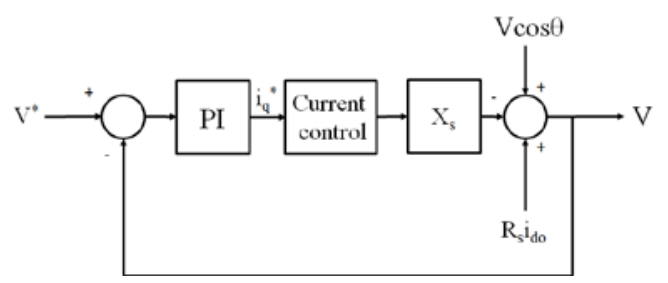

Fig. 4. Feedback AC voltage control.

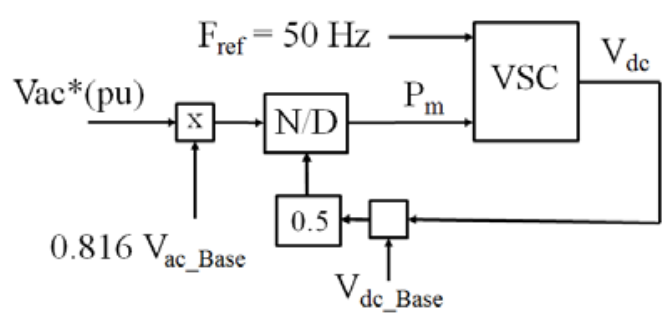

Fig. 5. Offshore AC voltage and frequency control.
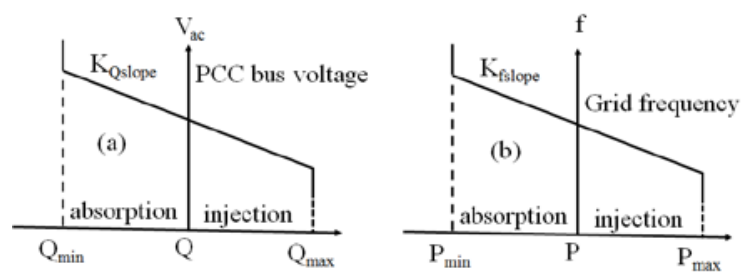

Fig. 6. VSC-HVDC droop characteristics: (a) $\mathrm{V}_{\mathrm{AC}}$-Q; (b) P-f.

\subsection{Control Scheme and Parameterization}

A number of different hierarchical control schemes can be used in a radial plus VSC-HVDC configuration. It has previously been shown that VSC-HVDC outer controllers and the control strategies used in different converters can significantly affect the AC-DC dynamics of the system [14]. Hence, in this study different combinations of the main control schemes, given in Table 1, are used to analyse the impact of a radial plus VSC-HVDC configuration on AC and DC side dynamics of the system. The $2^{\text {nd }}$ order approximation method has been used for tuning the inner current control loop and the feedback DC voltage control [16].

Since the closed loop transfer function of feedback active power, reactive power, and AC voltage control are in first order approximation form, the initial bandwidth of the controller is determined by the integral gain. Subsequently, the accurate parameters of these controllers are obtained by examining the frequency response of the closed loop transfer function. The final outer controller bandwidths and controller parameters used in this study are given in Table 2.

\begin{tabular}{|c|c|c|}
\hline $\begin{array}{c}\text { Control } \\
\text { scheme }\end{array}$ & Onshore converter & $\begin{array}{c}\text { Offshore } \\
\text { converter }\end{array}$ \\
\hline 1 & $\mathrm{~V}_{\mathrm{dc}}-\mathrm{Q}$ (both) & $\mathrm{V}_{\mathrm{ac}}-\mathrm{f}$ and PQ \\
\hline 2 & $\mathrm{~V}_{\mathrm{dc}}-\mathrm{Q}$ (both) & $\mathrm{V}_{\mathrm{ac}}-\mathrm{f}$ (droop) \\
\hline 3 & $\mathrm{~V}_{\mathrm{dc}}-\mathrm{Q}$ and $\mathrm{V}_{\mathrm{dc}}-\mathrm{V}_{\mathrm{ac}}$ & $\mathrm{V}_{\mathrm{ac}}-\mathrm{f}$ and PQ \\
\hline 4 & $\mathrm{~V}_{\mathrm{dc}}-\mathrm{Q}$ (both) & $\mathrm{V}_{\mathrm{ac}}-\mathrm{f}$ and $\mathrm{V}_{\mathrm{ac}}-\mathrm{P}$ \\
\hline 5 & $\mathrm{~V}_{\mathrm{dc}}-\mathrm{Q}$ and PQ & $\mathrm{V}_{\mathrm{ac}}-\mathrm{f}$ and $\mathrm{V}_{\mathrm{dc}}-\mathrm{Q}$ \\
\hline 6 & $\mathrm{~V}_{\mathrm{dc}}-\mathrm{V}_{\mathrm{ac}}\left(\mathrm{V}_{\mathrm{ac}} / \mathrm{Q}\right.$ droop) & $\mathrm{V}_{\mathrm{ac}}-\mathrm{f}$ (droop) \\
\hline
\end{tabular}

Table 1: Control scheme for converter stations.

\begin{tabular}{|c|c|c|}
\hline Controller & Bandwidth (Hz) & Parameter (pu) \\
\hline $\mathrm{V}_{\mathrm{dc}}$ & 2.57 & kp:17 ki: 208 \\
\hline $\mathrm{P}$ & 4.96 & kp: $0.001 \mathrm{ki}: 31$ \\
\hline $\mathrm{Q}$ & 4.06 & kp:0.00 ki: 25 \\
\hline $\mathrm{V}_{\mathrm{ac}}$ & 4.06 & kp:0.00 ki: 25 \\
\hline
\end{tabular}

Table 2: Controller bandwidths and control parameters.

\section{Simulation Results}

In order to compare the performance and the effect of different control schemes on system dynamics, the following disturbances have been applied to the system:

(a) Onshore AC system fault (3-phase,100 ms fault duration).

(b) Sudden outage of offshore wind generators.

(a) Onshore AC system fault - This case study investigates the radial plus AC-DC system dynamic behaviour under an onshore AC system fault. A self-clearing 3-phase fault has been applied to bus 9 of the system for $100 \mathrm{~ms}$, and the responses of the system's AC and DC side quantities are recorded to show the controller responses. It should be noted that future grid codes may differ the controller performance requirements. Fig. 7 shows the DC voltage responses of VSCHVDC converters for different control schemes as depicted in Table 1 . The power generation from the wind generator is not reduced during the fault at the onshore bus. Thus, an increase in DC voltage is anticipated as the power flow to the onshore grid from HVDC links are significantly reduced due to the fault at bus 9. From the figure, it can be seen that in most control cases the DC voltage is increased up to 1.03 pu during the onshore grid fault as the excess power during the fault is dissipated at the DC choppers. However, an exception can be observed for control scheme-5 where the DC voltage reaches $1.04 \mathrm{pu}$ at VSC-1 and -2 during the fault. For control scheme5 , at the instant of the onshore AC fault, VSC-3 (PQ control) cannot maintain the fixed power injection to the $\mathrm{AC}$ grid, therefore, the power absorption of the VSC-4 (Vdc-Q control) is reduced. This leads to the higher power flow through HVDC link-1. 

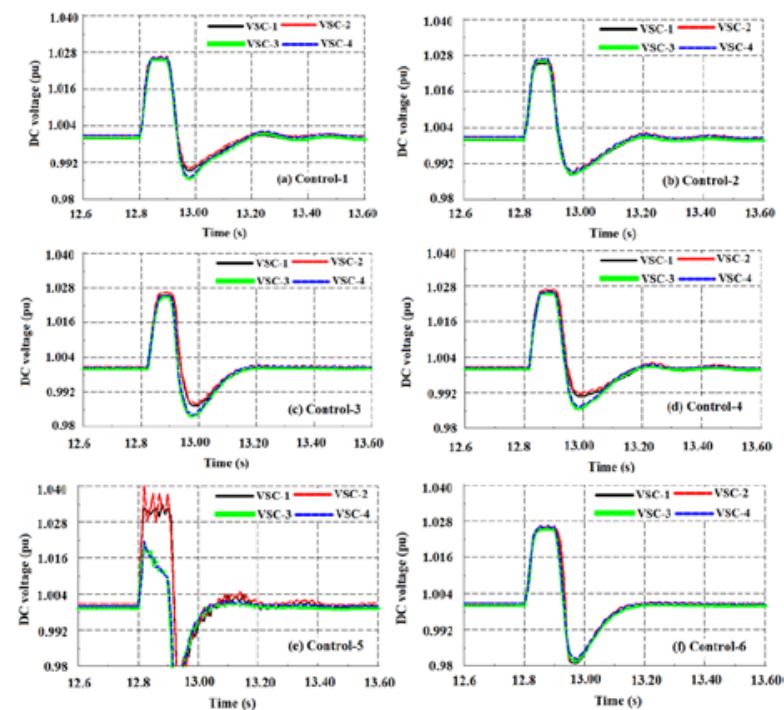

Fig. 7. DC voltage responses for a 3-phase fault at bus 9.

Fig. 8 shows the q-axis current responses for the converters following the onshore fault at bus 9 of the system. From the figure, it can be seen that following the fault clearance a sustained oscillation of q-axis current can be seen in onshore converters for control scheme -3. Additionally, for control scheme -6 , a sustained oscillation of q-axis current in both onshore converters is observed.
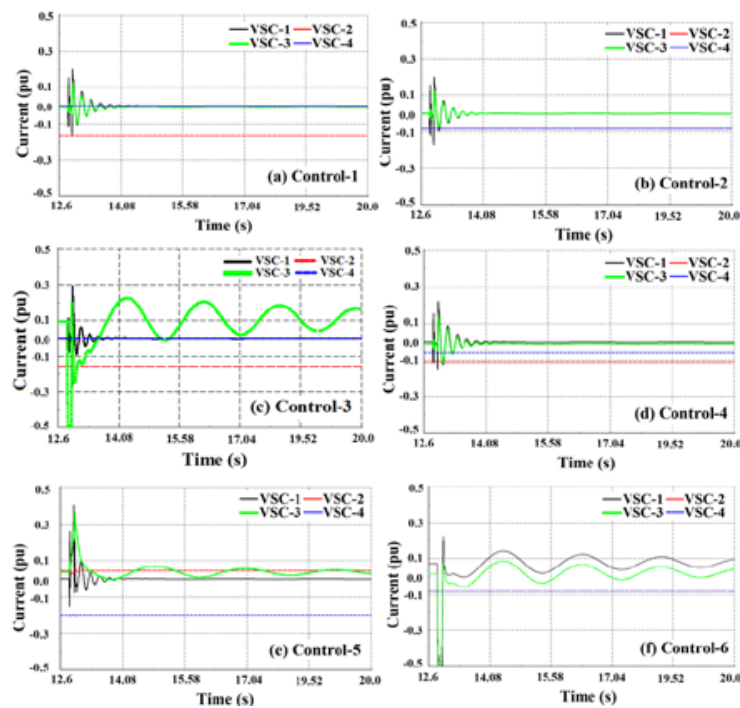

Fig. 8. q-axis current responses for a 3-phase fault at bus 9.

It is worth noting that AC voltage control is in use at the onshore converters for these control schemes (in control scheme -6 at both onshore converters and in control scheme 3 at VSC-3). For the AC voltage control, following the fault clearance, the AC voltage at the PCC does not fully recover sufficiently fast. A large uncontrolled transient of q-axis current and oscillations can be observed for the AC voltage controller, to some extent due to the susceptibility of the PLL to AC voltage distortion.

Fig. 9 shows the synchronous generator's electrical power responses for the onshore fault at bus 9. During the fault, the electrical power generation of the synchronous generators is reduced as anticipated. From the figure, it can be seen that in this case a sustained oscillation of synchronous generator electrical power can be seen for control schemes -3 and -6 . Moreover, in this case for control scheme -6, the higher transient overshoot of synchronous generator electric power for generator 4 can be observed.
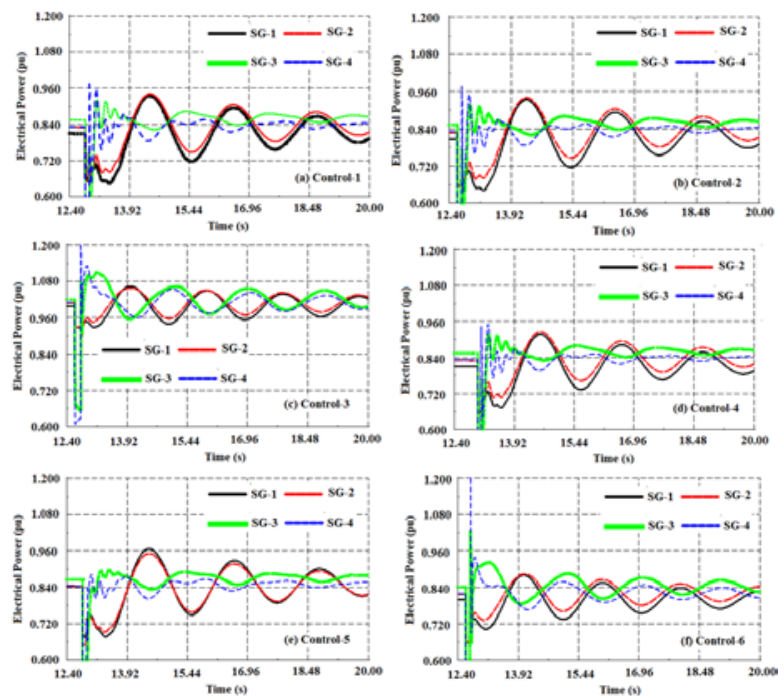

Fig. 9. Synchronous generator electrical power responses for a 3-phase fault at bus 9 .

(b) Sudden outage of wind generators - In this study the sudden outage of $315 \mathrm{MW}$ of offshore wind power is considered to investigate the performance of AC-DC system dynamics. For this particular case, scheduled active power flow through the offshore converter 2 (VSC-4, see Fig. 2) is set to $600 \mathrm{MW}$ for control schemes $-1,-3,-4$, and -5 to emphasise that these control schemes can show loop power flow through the HVDC-links. Fig. 10 shows the converter active power responses following the outage of offshore wind generators. From the simulation results shown in Fig. 10, reversed power flow through HVDC link-1 can be seen for control schemes-1,-3,-4, and-5.
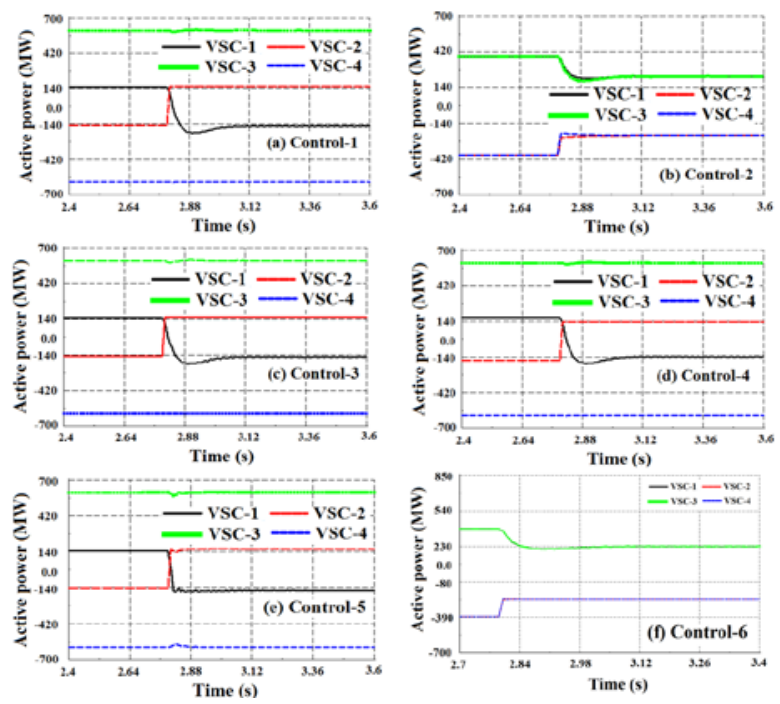

Fig. 10. VSC active power responses for the sudden outage of WPPs. 
Since the scheduled power flow through VSC-4 is $600 \mathrm{MW}$ for control schemes $-1,-3,-4$, and -5 , to maintain $600 \mathrm{MW}$ power through HVDC link-2, VSC-2 at link-1 (the sole grid forming converter in these cases) has started to feed HVDC link-2 at the instant of sudden wind generation loss.This leads to the power flow reversal in link-1. However, for control schemes -2 and -6 , the wind power generation reductions are equally shared by VSC-2 and -4 , as both of these converters have droop based AC voltage and frequency control.

Fig. 11 shows the DC voltage responses of the system following the outage of the offshore WPPs. To maintain the power balance across the HVDC links and the corresponding AC system at the instant of wind generator outage, the stored energy in the HVDC links is extracted for a considerable amount of time, resulting in DC link voltage reduction across the VSCs. As the scheduled power flow through link-2 is not altered for control schemes $-1,-3,-4$, and -5 , DC link voltage reduction at VSC -1 and -2 is only observed. On the other hand, DC link voltage reduction at all converters can be observed for control schemes -2 and -6 , since the reduction of wind power is equally shared by both HVDC links. For control schemes -2 and -6 , the reduction of DC link voltages is minimal. Moreover, for control scheme-5, higher reduction of DC link voltages can be observed.
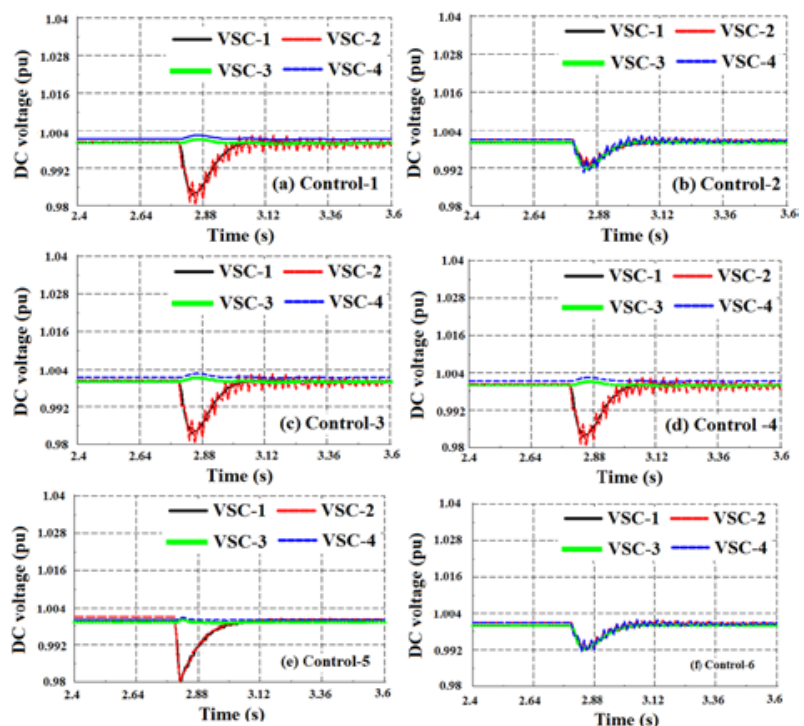

Fig. 11. DC voltage responses for the sudden outage of WPPs.

Transient stability assessment- The rotor angle of the interconnected generators has been used to evaluate the largedisturbance rotor angle stability or transient stability margin of the interconnected AC-DC system. It has been evaluated by using the transient stability index as given in (3)

$$
T S I=\frac{360^{0}-\delta_{M A X}}{360^{0}+\delta_{M A X}}
$$

where $T S I=$ transient stability index, $\delta_{\text {MAX }}=$ maximum rotor angle separation between two synchronous generators at any instant time. In this study, $\delta_{M A X}$ of any $\mathrm{i}^{\text {th }}$ generator is calculated with respect to the reference machine rotor angle which can be expressed as [17]

$$
\delta_{\text {MAX }}=\delta_{i}-\delta_{\text {ref }}
$$

If the TSI is less than zero, the system is large-disturbance rotor angle unstable. The power system is considered as stable for a TSI greater than zero. A higher TSI means a better transient stability margin of the system.

Fig. 12 shows the TSI of the system for different control schemes. From the figure, it can be observed that the differences are fairly small but that the system experienced the lowest TSI for control scheme-6. It is worth noting that the system has a better transient stability performance for control schemes $-1,-2$, and- 5 .

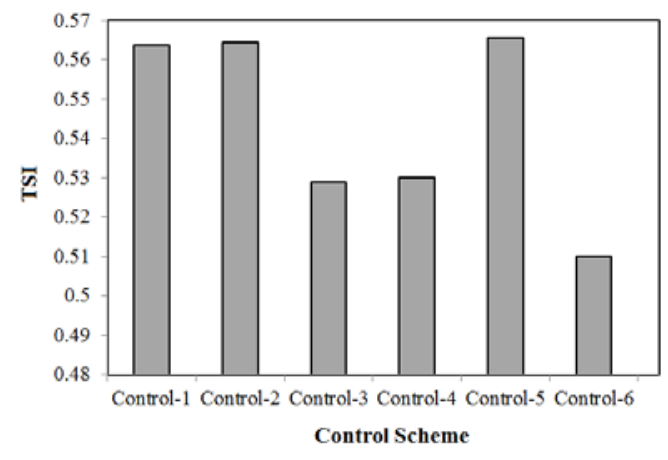

Fig. 12. Transient stability index (TSI).

Summary- Table 3 summarizes the impact of studied control schemes of a radial plus VSC-HVDC on AC-DC dynamics of the power system. From six different control schemes of a radial plus VSC-HVDC system, control scheme -2 is the most viable one, as it does not result in adverse effects on the ACDC dynamics of the system.

\section{Conclusions}

This study demonstrates the operation of a mixed AC-DC system where the offshore WPPs are interconnected to the grid via the parallel VSC-HVDC lines. Six different converter control schemes have been employed in the parallel VSCHVDC links to analyse the impact of this VSC-HVDC strategy on the AC-DC dynamics of the system. It is found that the control schemes of a radial VSC-HVDC can significantly affect the AC and DC dynamics of the system. Based on the results shown in this study it is evident that the system with grid forming converters at the offshore side and DC voltage-reactive power control at the onshore side is the most suitable control scheme for a radial plus VSC-HVDC strategy. However, this control scheme requires some form of coordinated control among offshore VSCs and WPPs for the secure and reliable operation of the DC grid.

The offshore AC voltage and frequency control used in this study is based on a direct control method. The stability and robustness of vector frequency control with droop have not 
been addressed in detail. Further research will be completed on this topic and will be reported in future.

\begin{tabular}{|l|l|}
\hline $\begin{array}{l}\text { Control } \\
\text { scheme }\end{array}$ & \multicolumn{1}{|c|}{ Remarks } \\
\hline Control-1 & $\begin{array}{l}\text { Negligible effect on AC-DC dynamics for an } \\
\text { onshore grid fault, however, results in power } \\
\text { flow reversal during the outage of WPPs. }\end{array}$ \\
\hline Control-2 & $\begin{array}{l}\text { Negligible effect on AC-DC dynamics for } \\
\text { both onshore and offshore disturbances. }\end{array}$ \\
\hline Control-3 & $\begin{array}{l}\text { Sustained q-axis current and synchronous } \\
\text { generator power oscillations for an onshore } \\
\text { fault. Results in power flow reversal during } \\
\text { the outage of WPPs. }\end{array}$ \\
\hline Control-4 & $\begin{array}{l}\text { Negligible effect on AC-DC dynamics for an } \\
\text { onshore grid fault, however, results in } \\
\text { power flow reversal during the outage of } \\
\text { WPPs. }\end{array}$ \\
\hline Control-5 & $\begin{array}{l}\text { The possibility of higher DC voltage } \\
\text { variations on HVDC link-1. Sustained q-axis } \\
\text { current oscillation. Results in power flow } \\
\text { reversal during the outage of WPPs. }\end{array}$ \\
\hline Control-6 & $\begin{array}{l}\text { Sustained q-axis current and synchronous } \\
\text { generator power oscillations for an onshore } \\
\text { fault. }\end{array}$ \\
\hline
\end{tabular}

Table 3: Summary of comparison for different control schemes.

\section{Acknowledgements}

This work is supported by EPSRC project on Multi-Terminal VSC-HVDC Networks - Grid Control (EP/L021463/1). We would like to thank Andrzej Adamczyk, Alstom Grid, for the helpful comments during this work.

\section{References}

[1] "Offshore wind: Opportunities for the composite industry," The Crown Estate, [online] available at http:// www.thecrownestate.co.uk [Accessed 24 July 2015], June 2011.

[2] A. Hiorns, R. Smith, and D. Wright, "An integrated approach to offshore electricity transmission," in the $9^{\text {th }}$ IET International Conference on AC and DC Power Transmission (AC/DC 2010), London, UK, 2010.

[3] "UK future energy scenario: UK gas and electricity transmission,” National Grid Electricity Transmission plc: [online] available at http://www.nationalgrid.com [Accessed 25 July 2015], June 2014.

[4] N. R. Chauduri, B. Chauduri, R. Majumder, A. Yazdani, Multi-terminal Direct Current Grids: Modelling, Analysis and Control. NJ, USA: John Wiley \& Sons, inc., 2014.

[5] A. Arulampalam, G. Ramtharan, N. Caliao, J. B. Ekanayake, and N. Jenkins, "Simulated onshorefault ride through of offshore windfarm connected through VSC-HVDC,” Wind Energy, Volume 32, pp. 103-113, 2008.

[6] Friends of super grid, "Position paper on the EC Communication for a European Infrastructure Package," EnergiRike [online] available at http://www.energirike.no [Accessed 26 July 2015], 2011.

[7] W. Wang, M. Barnes, O, Marjanovic, and O. Cwikowski, "Impact of DC breaker systems on multi-terminal VSC-HVDC stability," IEEE Trans. Power Delivery, Early access, 2015.

[8] X. Hu, J. Liang, D. J. Rogers, and Y. Li, "Power flow and power reduction control using variable frequency of offshore AC grids," IEEE Trans. Power Systems, Volume 28, pp. 3897-3905, 2013.

[9] J. Stevens, D. J. Rogers, "Control of multiple VSCHVDC converters within an offshore AC-hub," in IEEE Energy Tech Conference, Cleveland, OH, USA, 21-23 May 2013.

[10] J. Weizenbeck, “AC hub for offshore wind power connected with HVDC transmission system," MSc thesis, Universitat Politecnica De Catalunya, Spain, 2013.

[11] P. Kundur, N. J. Balu, and M. G. Lauby, Power System Stability and Control, New York, USA: McGraw-Hill, 1994.

[12] DIgSILENTGmbH, "DIgSILENT Power Factory V 15.1-User Manual,” DIgSILENTGmbH, 2014.

[13] M. Mohammadi, M. Avendano-Mora, M. Barnes, J. Y. Chen, "A study on fault ride-through of VSC connected offshore wind farms," in IEEE Power and Energy Society General Meeting, British Columbia, Canada, 21-25 July 2013.

[14] Li Shen, "Model integration and control interaction analysis of AC/VSC HVDC system," Ph.D. Dissertation, School of Electrical and Electronic Engineering, The University of Manchester, 2015.

[15] T. M. Hailesellasie, R. E. Torres-olguin, T. K. Vrana, K. Uhlen, and T. Underland, "Main grid frequency support strategy for VSC-HVDC connected wind farms with variable speed wind turbines," in IEEE PowerTech Conference. Trondheim, Trondheim, Norway, 19-23 June 2011.

[16] R. C. Dorf, R. H. Bishop, Modern Control Systems, Upper Saddle River, NJ, USA: Prentice Hall, 2001.

[17] L. Shi, S. Dai, Y. Ni, L. Yao, and M. Bazargan, "Transient stability of power systems with high penetration of DFIG based wind farms," in IEEE Power and Energy Society General Meeting, Calgary, Alberta, Canada, 26-30 July, 2009. 